\title{
PHYTOCHEMICAL SCREENING AND ANTIBACTERIAL ACTIVITY OF Garcinia kola SEED EXTRACTS AGAINST PATHOGENIC METHICILLIN RESISTANT Staphylococcus aureus
}

\author{
Nas, F. S., ${ }^{1}$ Zage, A. U. ${ }^{2}$ and *Ali, M. ${ }^{2}$ \\ Biological Science Department, Bayero University Kano \\ ${ }^{2}$ Microbiology Department, Kano University of Science and Technology Wudil Kano \\ *Correspondence author: alimuhd4real@gmail.com
}

\begin{abstract}
The study was aimed to determine the phytochemical constituents and antibacterial activity of Garcinia kola seeds extracts against pathogenic Methicillin Resistant Staphylococcus aureus (MRSA). Total of 54 Staphylococcus aureus isolates from infected wound and urine were collected from Abubakar Imam Urology Center in Kano State, Nigeria over a period of seven month (December, 2016 to July, 2017), out of which 5 methicillin resistant isolates were found and tested against the extracts. Phytochemical screening of the seeds extracts indicated the presence of Alkaloid, Tannin, Saponin, and Cardiac glycoside, Flavonoid, Terpenoid, Phenols, Anthraquinone and Steroid. However, reducing sugar is absent. The antibacterial activity of the extracts against the isolates showed that ethanol extract is more effective (with average zone of inhibition of $15.25 \mathrm{~mm}$ ) when compared to aqueous extract $(14.37 \mathrm{~mm})$. The Minimum Inhibitory Concentration (MIC) and Minimum Bactericidal Concentration (MBC) of the extracts ranges from 12.5 $100 \mathrm{mg} / \mathrm{ml}$ of the extracts. Statistical analysis of the result showed that there is no significant different on the susceptibility of the organisms against the extracts. Findings from this work support the use of seed extracts from G. kola as medicinal plant.

Keywords; Antibacterial activity, Garcinia kola, Methicillin Resistant Staphylococcus aureus, phytochemical.
\end{abstract}

\section{INTRODUCTION}

The medicinal values of plants lie in the chemical substances presents in the parts of the plant such as seed, leaves bark and root. These substances produce definite physiological action in the human body. Despite modern development in the treatment of diseases, herbal remedies have been continuous and universal. Modern medicines have always depended on herbal extracts from plants as fundamental source of therapeutic ingredients. Some naturally occurring substances in plants play significant role in plant disease resistance and thus most bacteria are sensitive to extract from these plants. Plants are pools of potential antimicrobial compounds for pharmaceutical need. The array of active compounds derived from them have impressive pharmaceutical properties such as analgesics, aesthetic, antibiotics, anti-parasitic, anti-inflammatory, oral contraceptive, hormones, ulcer therapeutic laxative. Seeds, herbs, vegetables, bark, roots accumulate in their cells a great variety of phytochemical compounds such as alkaloids, tannins, saponins, phenolic compounds (Cowan, 1999).

Garcinia kola is forest tree indigenous to sub-Saharan Africa and has been referred to as a 'wonder plant' because almost every part of it has been found to be of medicinal importance (Dalziel, 1948). It occurs naturally from Sierra Lone to Southern Nigeria and on into Zaire and Angola, but is further distributed by man and is often found cultivated around villages. Garcinia kola belongs to a family of tropical plants known as Guttifera. It is an evergreen tree grown in the tropical rainforest of West Africa, (Burkhill, 1985).
It grows to a height of about 30metres high, and the fruit, which is in the size of an orange, is smooth and reddish yellow with peach-like skin and yellow pulp and contains three or four seeds covered with brown seed coat (Aniche and Uwakwe, 1990). The seed is an edible nut, generally known and called Bitter Kola in Nigeria, and commonly called "Namiji goro" in Hausa, Orogbo in Yoruba and "Aku-ilu" in Igbo. The seed (commonly known as bitter kola, male kola or false kola) is a masticatory used in traditional hospitality, cultural and social ceremonies. Extractive of the plant have been traditionally used for ailments such as laryngitis, liver diseases and cough. The seeds are used to prevent or relieve colic, cure head or chest colds and relieve cough (Iwu et al., 1999). The seed also has anti-inflammatory, antimicrobial, antidiabetic and antiviral as well as antiulcer properties (Iwu et al., 1990).

Staphylococcus aureus is a bacterium of significant importance because of its ability to cause a wide range of diseases and capacity to adapt to diverse environmental forms (Waldvogel, 2000). The organism colonizes skin, skin glands and mucous membrane, causing infections both in human and animals such as rashes, inflammations of bones and the meninges as well as septicaemia (Aklilu et al., 2010). In addition, $S$. aureus causes inflammation of the mammary gland in bovine and the lower part of the foot in poultry (Quinn et al., 2000). Penicillin and its derivatives, including methicillin have been used for the treatments of infections caused by $S$. aureus (Rayner and Munckhof, 2005). 
Bajopas Volume 10 Number 2 December, 2017

However, certain strains of $S$. aureus developed resistance known as methicillin resistant Staphylococcus aureus (MRSA). At present, less than $90 \%$ of $S$. aureus strains are resistant to most penicillin derivatives (Freeman-Cook and FreemanCook, 2006) and ordinary antimicrobial agents like drugs from the family of aminoglycosides, macrolides, chloramphenicols, tetracyclines and fluoroquinolones (Lee, 2003).

\section{MATERIALS AND METHODS}

\section{Ethical Approval}

Ethical approval for this research was obtained from the Hospitals Management Board (HMB) via the consent of Abubakar Imam Urology Centre Ethical Committee.

\section{Sample Collection}

Fifty four (54) Staphylococcus isolates were collected from Abubakar Imam Urology Center in Kano State, Nigeria over a period of seven months (December 2016 to July 2017). The isolation of Staphylococcus isolates were made from wounds/pus (24 isolates) and urine (30 isolates). Discrete colonies of each isolate were kept in Nutrient agar slant and then stored at $4^{\circ} \mathrm{C}$ for further experiments (Nas and Ali, 2017).

\section{Identification of Bacteria}

The isolates were confirmed as Staphylococcus aureus by conventional microbiological methods: Gram staining, Biochemical test (Coagulase test and Catalase test) and Mannitol fermentation test. Gram staining was done according to the methods described by Chessbrough (2010). Coagulase and Catalase tests were done according to the method described by Holt et al. (1994). Mannitol fermentation test was done by inoculating the isolates onto the surface of Mannitol Salt agar and incubated at $37{ }^{\circ} \mathrm{C}$ for 24 hours (Holt et al., 1994)

\section{Identification of Methicillin Resistant Bacteria}

Fifty four (54); isolates confirmed as Staphylococcus aureus were later subjected to antimicrobial sensitivity testing for methicillin resistant using modified Kirby Bauer diffusion method on Muller Hinton agar and incubated for 24 hours at $37{ }^{\circ} \mathrm{C}$. The methicillin resistant were tested using commercially prepared antibiotics discs containing Oxacillin (1 mg disc), Ampicillin (2mg), Tetracycline (5mg), Cefoxitin (30mg), and Ceftriaxone (15mg) discs. The inoculums suspension was adjusted to match 0.5 McFarland turbidity standards. A sterile cotton swab was dipped into the adjusted suspension and excess inoculums was removed by pressing the swab firmly on the inside wall of the tube. The solidified surface of Mueller Hinton agar plate was inoculated by streaking the swab over the entire surface. The antimicrobial discs were placed firmly on the surface of the inoculated agar plate using sterile forceps. The plates were incubated at $37{ }^{\circ} \mathrm{C}$ for 24 hours. The plates were examined and the diameters of the zones of inhibition were measured. Results were classified as susceptible, intermediate, or resistant, according to the approved guidelines of the Clinical and Laboratory Standards Institute (CLSI, 2011).

\section{Plant Material}

\section{Collection, Identification and Processing}

The plant material used in this study were seeds of Garcinia kola which were obtained from Sabon gari market in Kano, Authentication of the plant materials was done at Herbarium unit in the Department of Plant Biology, Bayero University Kano. The plant material was authenticated with the following Herbarium accession number BUKHAN 307 (DPB/BUK/HIF/0667) specimens were deposited there for future references. The seeds of Garcinia kola were removed from the seed coat and neatly washed with distilled water, air dried for two weeks and crushed to fine powder using sterile mortar and pestle under laboratory condition. The powdered form of the seed were placed in air tight containers and stored for further use.

\section{Preparation of Extracts}

The solvent extracts of the plant were prepared in accordance with the description of Akerele et al. (2008) with slight modification. Briefly, 50 grams of the powder was steeped in $500 \mathrm{ml}$ of the respective solvent (ethanol, and distilled water) for 7 days with vigorous shaking. The resultant extracts were then filtered using Whatman No.1 filter paper. The filtrates were evaporated to powder using rotary evaporator and water bath for ethanol and aqueous solutions respectively. One gram (1g) of each extracted powder, were measured and dissolved in $5 \mathrm{ml}$ of $10 \%$ Dimethylsulphoxide (DMSO). Thus $200 \mathrm{mg} / \mathrm{ml}$ of stock was obtained as a standard concentration of both aqueous and ethanol extracts.

\section{Phytochemical Screening}

A small portion of each extract was subjected to the phytochemical test using Tiwara et al. (2010) and Sofowora (1993) methods as described by Adegboye et al., (2008) to test for alkaloids, tannins, flavonoids, steroids, saponins, reducing sugars and cardiac glycoside.

\section{Antibacterial Susceptibility Test}

The sensitivity of each extracts was determined using the agar well diffusion method as described by Ahmed and Beg (2001), with modifications. The prepared bacterial suspension equivalent to 0.5 McFarland Standard $\left(1.5 \times 10^{6} \mathrm{CFU}\right)$ was inoculated into sterile Mueller- Hinton agar medium in a sterile Petri-dish. A sterile $6 \mathrm{~mm}$ diameter cork borer was used to bore 5 wells into the agar medium. The wells were then filled up with approximately $0.1 \mathrm{ml}$ of the extract solution at a concentration of 50,100, 150 and $200 \mathrm{mg} / \mathrm{ml}$ taking care to prevent spillage onto the surface of the agar medium. The plates were allowed to stand on the laboratory bench for 1 hour to allow proper diffusion of the extract into the medium after which the plates were incubated at $37^{\circ} \mathrm{C}$ for 24 hours, and thereafter the plates were observed for zones of inhibition and measured. Ciprofloxacin $125 \mathrm{mg} / \mathrm{ml}$ from Micro Lab limited was used as a positive control.

\section{Determination of Minimum Inhibitory Concentration (MIC)}

The MIC of the extracts was determined using broth dilution technique. Two fold serial dilutions of the extracts were prepared by adding $2 \mathrm{ml}$ of $200 \mathrm{mg} / \mathrm{ml}$ of the extract into a test tube containing $2 \mathrm{ml}$ of Nutrient broth, thus producing solution containing $100 \mathrm{mg} / \mathrm{ml}$ of the extract. 
Bajopas Volume 10 Number 2 December, 2017

The process continue serially up to test tube No. 5, hence producing the following concentrations; 100, $50,25,12.5,6.25 \mathrm{mg} / \mathrm{ml}$. Test tube No. 6 do not contain extracts and serve as negative control. Exactly $0.5 \mathrm{ml}$ of 0.5 McFarland equivalent standards of test organisms were introduced into the test tubes and incubated at $37{ }^{\circ} \mathrm{C}$ for 24 hours. After incubation the test tubes were observed for growth by checking for turbidity (Ahmed and Beg 2001).

\section{Determination of Minimum Bactericidal} Concentration (MBC)

From each tube that did not show visible growth in the MIC, $0.1 \mathrm{ml}$ was aseptically transferred into extract free Mueller Hilton agar plates. The plates were incubated at $37{ }^{\circ} \mathrm{C}$ for 24 hours. The MBC was recorded as the lowest concentration (highest dilution) of extract that had less than $99 \%$ growth on nutrient agar plates (Ahmed and Beg 2001).

\section{Statistical Analysis}

The data of average zone of inhibition produced by the isolates against the antibiotics used was analyzed using One-Way ANOVAs and the statistical program SPSS 21.0 (Statistical Package for the Social Sciences). The results were presented as the means \pm standard deviation. Significance level for the differences was set at $p<0.05$.

\section{RESULTS}

\section{Sensitivity Test}

Antibiotic resistance test was conducted for the $54 \mathrm{~S}$ aureus isolates, and the zones of inhibition obtained were classified based on clinical and laboratory standards institute (2012) in Tables 1. The antibiotic sensitivity test of the $S$. aureus isolates from wounds and urine showed that 5 isolates were resistant to the beta - lactam antibiotics used with equal resistance to Oxacillin, Ampicillin and Cefoxitin. The sensitivity test of the $S$. aureus isolates showed that wounds isolates have the highest resistance to the antibiotics used 3 $(60 \%)$, while urine isolates have 2 (40\%).

Table 1 Distribution of MRSA from Wound and Urine Samples

\begin{tabular}{lccc}
\hline Isol. Source & No. of isolate & S. aureus +ve & MRSA +ve \\
\hline Wound & 24 & $24(44 \%)$ & $3(60 \%)$ \\
Urine & 30 & $30(56 \%)$ & $2(40 \%)$ \\
Total & $\mathbf{5 4}$ & $\mathbf{5 4}(\mathbf{1 0 0 \% )}$ & $\mathbf{5 ( 1 0 0 \% )}$ \\
\hline
\end{tabular}

\section{Phytochemical Screening}

Phytochemical screening of the seeds extracts is presented in Table 2. The results indicated the presence of Alkaloid, Tannin, Saponin, and
Cardiac glycoside, Flavonoid, Terpenoid, Phenols Anthraquinone and Steroid. However, reducing sugar is absent.

Table 2: Phytochemical Screening of Seeds Extracts of G. kola

\begin{tabular}{lc}
\hline Phytochemical & Seed extract \\
\hline Alkaloids & + \\
Anthraquinone & + \\
Phenols & + \\
Cardiac Glycosides & + \\
Flavonoid & + \\
Terpenoid & + \\
Saponin & + \\
Steroids & + \\
Tannins & - \\
Reducing sugar & \multicolumn{1}{c}{ Key + = Presence of Phytochemical $-=$ Absent of Phytochemical }
\end{tabular}

Key $+=$ Presence of Phytochemical, - = Absent of Phytochemical

Antibacterial Activity of the Extracts

The antibacterial activity of the plant aqueous and ethanol seeds extracts against the isolates is presented in Table 3. The result shows that highest antibacterial activity against isolate 3 and
5 with zone of inhibition of $19.00 \mathrm{~mm}$ each at $200 \mathrm{mg} / \mathrm{ml}$ while no zone of inhibition shown by isolate 4 at concentration of 50 and $100 \mathrm{mg} / \mathrm{ml}$. Zone of inhibition shown by control (Ciprofloxacin $125 \mathrm{mg} / \mathrm{ml})$, ranges from $17.00-22.00 \mathrm{~mm}$.

Table 3: Zone of Inhibition of Different Concentration of the Garcinia kola Extracts against MRSA

\begin{tabular}{|c|c|c|c|c|c|c|}
\hline \multirow[t]{2}{*}{ Extracts } & \multirow[t]{2}{*}{ Conc. $(\mathrm{mg} / \mathrm{ml})$} & \multicolumn{5}{|c|}{ Isolates/zones of inhibition (mm) } \\
\hline & & Is1 & Is2 & Is3 & Is4 & Is5 \\
\hline \multirow[t]{4}{*}{ ESE } & 50 & 12 & 10 & 06 & 06 & 11 \\
\hline & 100 & 15 & 11 & 10 & 06 & 12 \\
\hline & 150 & 14 & 15 & 11 & 09 & 15 \\
\hline & 200 & 18 & 15 & 19 & 10 & 19 \\
\hline \multirow[t]{4}{*}{ ASE } & 50 & 10 & 06 & 10 & 06 & 12 \\
\hline & 100 & 13 & 11 & 10 & 06 & 15 \\
\hline & 150 & 14 & 11 & 12 & 06 & 16 \\
\hline & 200 & 15 & 13 & 16 & 10 & 18 \\
\hline Contrl & 125 & 21 & 19 & 19 & 17 & 22 \\
\hline
\end{tabular}

Key: ESE $=$ Ethanol Seeds Extract, ASE $=$ Aqueous Seed Extract, Is $=$ Isolates

Control $=$ Ciprofloxacin $(125 \mathrm{mg} / \mathrm{ml})$ 


\section{Minimum Inhibitory Concentration (MIC) of the Extracts}

Minimum Inhibitory Concentration of ethanol seed extract is represented in Table 4 which showed dilutions of various concentrations of the ethanol seed extract against test isolates. Lower MIC was recorded in isolate $1(12.5 \mathrm{mg} / \mathrm{ml})$ while highest MIC was recorded in isolate 3 and $4(100 \mathrm{mg} / \mathrm{ml})$. Minimum inhibitory concentration of aqueous seed extract shows dilutions of various concentrations of the aqueous seed extract of against test organisms. Lower MIC was recorded in isolate $5(12.5 \mathrm{mg} / \mathrm{ml})$ while highest MIC value was recorded in isolate 2 and $4(100 \mathrm{mg} / \mathrm{ml}$ each).

Table 4: Minimum Inhibitory Concentration (MIC) of Garcinia kola Seeds Extracts against MRSA Isolates/ MIC (mg/ml)

\begin{tabular}{llllll}
\hline Extracts & Is1 & Is2 & Is3 & Is4 & Is5 \\
\hline ESE & 12.5 & 25.0 & 100 & 100 & 25 \\
ASE & 25 & 100 & 25 & 100 & 12.5 \\
\hline
\end{tabular}

Key: ESE = Ethanol Seeds Extract, ASE = Aqueous Seed Extract, Is $=$ Isolates, $\mathrm{NF}=$ Not found

Minimum Bactericidal Concentration (MBC)

Minimum Bactericidal Concentration of ethanol seeds extract is represented in Table 5 which showed that the plant extracts can kill some test isolates at concentration of $25-100 \mathrm{mg} / \mathrm{ml}$. However, some isolates are resistant to the extracts. Both extracts could not kill isolate 4 while isolate 2 is resistant to aqueous seed and stem back extracts.

Table 4.9 Minimum Bactericidal Concentration (MBC) of Garcinia kola Seeds Extracts against MRSA

\begin{tabular}{|c|c|c|c|c|c|}
\hline \multirow[b]{2}{*}{ Extracts } & \multicolumn{4}{|c|}{ Isolates/ MBC $(\mathrm{mg} / \mathrm{ml})$} & \multirow[b]{2}{*}{ Is5 } \\
\hline & Is1 & Is2 & Is3 & Is4 & \\
\hline ESE & 25 & 25 & 100 & $\mathrm{NF}$ & 50 \\
\hline ASE & 25 & $\mathrm{NF}$ & 50 & NF & 25 \\
\hline
\end{tabular}

Key: $\mathrm{ESE}=$ Ethanol Seeds Extract, $\mathrm{ASE}=$ Aqueous Seed Extract,

Is $=$ Isolates, $\mathrm{NF}=$ Not found

\section{DISCUSSION}

The Phytochemical screening of the plant parts revealed the presence of Alkaloid, Tannin, Saponin, and Cardiac glycoside, Flavonoid, Terpenoid, Phenols Anthraquinone and Steroid. However, reducing sugar is absent. The finding of this study was in conformity with that of Adegboye et al. (2008) on phytochemical screening of Garcinia kola, in which the results shows that Garcinia kola seeds contain steroids, cardiac glycosides, flavonoids, tannins, saponins and reducing sugars. The presence of the above phytochemicals in the plant parts was responsible for its antibacterial activity (Akerele et al., 2008). Garcinia kola seeds flavonoids have been shown to possess antiinflammatory and anti-hepatotoxic properties (Braide, 1991) as well as antimicrobial activities (Madubunyi, 1995). Saponins are known to possess antibacterial activities (Gonzalez-Lamothe et al., 2009; Cowan, 1999) whilst tannins play an important role in wound healing, and also possess some antimicrobial activities (Cowan, 1999). Complex mixtures of steroid compounds from plants are known to exhibit some bioactivity. Phytochemical and biochemical studies of Garcinia kola showed the presence of sterols, terpenoids, flavonoids, glycosides, pseudo-tannins, saponin, proteins and starch (Madubunyi, 1995). This result was also in line with the present study.

The antibacterial activity of the plant showed that the plant part extracts demonstrated an antimicrobial effect against the test isolates with higher activity in ethanol extract compared to aqueous extract. This demonstrated that the organic extracts were more effective than aqueous extracts. This may be due to the better solubility of the active components in the organic solvent. Doughari et al. (2007) stated that the anti-microbial effect of this plant could be due to the bioactive compounds such as the phytochemicals constituent present in the plant. On susceptibility of the isolates against the extract, the results showed that highest antibacterial activity was demonstrated against isolate 3 and 5 with zone of inhibition of $19.00 \mathrm{~mm}$ each at $200 \mathrm{mg} / \mathrm{ml}$, while no zone of inhibition shown by isolate 4 at concentration of 50 and $100 \mathrm{mg} / \mathrm{ml}$. The antibacterial activity of the plant aqueous seed extract against isolates shows that highest antibacterial activity was demonstrated against isolate 5 with zone of inhibition of $18.00 \mathrm{~mm}$ at $200 \mathrm{mg} / \mathrm{ml}$ while no zone of inhibition shown by isolate 2 and 4 at concentration of 50 and $100 \mathrm{mg} / \mathrm{ml}$. In line with the present finding, several other studies have reported antimicrobial potentials. The plant is used for the treatment of liver disorders and has been shown to possess anti-inflammatory, antimicrobial, antioxidant, antiviral, antidiabetic and anti-hepatotoxic activities (Iwu et al., 1999). The seeds are used in the treatment of bronchitis, throat infections, colics, headaches, chest colds, coughs, diarrhoea, hepatitis, asthma and dysmenorrheal/menstrual cramps (Iwu et al., 1999). The seed has also shown broad spectrum antibacterial activities (Ezeifeka et al., 2004). This result of this finding is in consistency with the investigation as reported by Ogbogu et al. (2010), on the antimicrobial efficacy of cold, hot water extracts and ethanol extract of $G$. kola which revealed that cold and hot water extract of $G$. kola moderately inhibited the growth of Staphlococcus aureus and Streptococcus pyogenes with zone of inhibition of between $9-15 \mathrm{~mm}$, he also found the cold and 
hot ethanol G. kola extracts profoundly inhibited the growth of $S$. aureus, $S$. pyogenes, E. coli and $S$. typhi to about 13 to $21 \mathrm{~mm}$. From the results of MIC and MBC determination, it showed that at concentration of $12.5-100 \mathrm{mg} / \mathrm{ml}$, the extracts extract can inhibit the growth or kill the organisms.

\section{CONCLUSION}

The findings of this study revealed that the seeds extract Alkaloid, Tannin, Saponin, and Cardiac glycoside, Flavonoid, Terpenoid, Phenols Anthraquinone and Steroid. The antibacterial activity of the plant seed extract showed that the extracts demonstrated antimicrobial effect against the test isolates with higher activity in ethanol extract when compared to aqueous extract. The antibacterial activity of the plant parts is due to the presence of the phytochemicals identified in this study. The Minimum Inhibitory Concentration (MIC) and

\section{REFERENCES}

Adegboye, M. F., Akinpelu, D. A. and Okoh, A., (2008). The Bioactive and Phytochemical Properties of Garcinia kola (Heckel) Seed extract on some Pathogens, Afr. J. Biotechnol. 7:3934-3938

Ahmed, I. and Beg, A.Z. (2001). Antimicrobial and phytochemical studies on 45 Indian Medicinal plants against multi-drug resistance human pathogens. $J$ Ethnopharmacol 74, 113-123.

Akerele, J. O., Obasuyi, O., Ebomoyi, M. I., Oboh, I. $\mathrm{E}$. and Uwumarongie, $\mathrm{O}$. $\mathrm{H}$. (2008).Antimicrobial activity of ethanol extract and fractions of the seeds of Garcinia kola Heckel (Guttiferae). Africa J. Biotechnol. 7(2):169-172.

Aklilu, E., Zunita, Z., Hassan, L. and Chen, H. C. (2010). Phenotypic and genotypic characterization of methicillin-resistant Staphylococcus aureus (MRSA) isolated from dogs and cats at University Veterinary Hospital, Universiti Putra Malaysia. Trop. Biomed. 27(3): 483-492.

Aniche, G.N. and Uwakwe, G.U. (1990). Potential use of Garcinia kola as hope substitute in large beer brewing. World. J. Microbiol. Biotechnol. 6: 323-327.

Braide, V.B. (1991). Antihepatotoxic biochemical effect of Kolaviron, a biflavonoid of Garcinia kola seeds. Phytother. Res., 5:35-37.

Burkill, H. M. (1985). Useful plants of West Tropical Africa. White Friars Press Ltd., United Kingdom. 1: 300-301.

CLSI. (2007). Performance standards for antimicrobial susceptibility testing; Seventeenth informational supplement. Clinical and Laboratory Standards Institute. 27(1):M100S17. Available:www.clsi.org (Accessed on October 01, 2014)

Cheesbrough, M. (2002). District Laboratory Practice in Tropical Countries, Part 2. Cambridge University Press: 135-142, 158-159.

Cowan, M.M. (1999). Plants products as antimicrobial agents. Clin. Microbiol. Rev.12(4): 564-582.
Minimum Bactericidal Concentration (MBC) of the extracts ranges from $12.5-100 \mathrm{mg} / \mathrm{ml}$ of the extracts. Findings from this work support the use of seed extracts from $G$. kola as medicinal plant. It is recommended thatnattempts should be made to purify, characterize and produce a standardized antimicrobial drug from Garcinia kola extract

\section{Author's contribution}

This work was carried out in collaboration between both authors. Both the authors designed the study, conduct the experiment and performed the statistical analysis and wrote the first draft of the manuscript. Author FSN managed the literature searches. Both authors read and approved the final manuscript.

Conflict of interest

Authors have declared that no conflicts of interests exist.

Dalziel, J. M. (1948). The useful plants of West Tropical Africa. Crown Agents for the Colonies, London. 45-48

Deurenberg, R.H., and Stobberingh, E.E. (2008). The evolution of Staphylococcus aureus. Infect. Genet. Evol. (6):747-763.

Doughari, J. H., El Mahmud, A. M and Manzara, S. (2007). Studies on the antibacterial activities of root extract of Carica papaya L. African Journal of Microbiology Research. Pp. 037041.

Ezeifeka, G.O., Orji, M.U., Mbata, T.I. and Patrick, A.O. (2004). Antimicrobial activities of Cajanus cajan, Garcinia Kola and Xylopia aethiopica on pathogenic microorganisms. Biotechnol. 3(1): 41-43.

Freeman-Cook, L and Freeman-Cook, K. (2006). Staphylococcus aureus infections. Chelsea house publishers, USA.

Gonzalez-Lamothe, R., Mitchell, G., Gattuso, M., Diarra, M.S., Malouin, F. and Bouarab, K. (2009). Plant antimicrobial agents and their effects on plant and human pathogens. $J$. Mol. Sci. 10: 3400-3419.

Holt, J.G., Krieg, N.R., Senath, P.H.A., Staley, J.T. and Williams, S.T. (1994). Bergey's Manual of Determinative Bacteriology 9th Ed. Baltimore Md Williams and Wilkins

Iwu, M.A., Duncan, R. and Okunji, C.O. (1999). New antimicrobials of plant origin (www.hort.purdue.edu)

Iwu M.M., Igboko A.O. and Tempesta M.S. (1990). Biflavonoid constituents of Gacinia Kola roots Fitoterapic 61 (2): $178-181$.

Lee, J. H. (2003). Methicillin (Oxacillin)-resistant Staphylococcus aureus strains isolated from major food animals and their potential transmission to humans. Appl. Environ. Microbiol. 69(11): 6489-6494. http://dx.doi.org/10.1128/AEM.69.11.6489$6494.2003 \quad$ PMid:14602604 PMCid:PMC262320

Madubunyi, I. I. (1995). Antimicrobial Activities of the Constituents of Garcinia kola seeds. Intern. J. Pharmacog., 33:232-237. 
Nas, F. S. and Ali, M. (2017). Antibacterial Activity of Boswellia dalzielii Leaves Extracts against Some Pathogenic Bacterial Isolates. Journal of Advances in Microbiology 7(1): 1-8 DOI: 10.9734/JAMB/2017/37690

Ugbogu, O. C., Ahuama, O. C., Atusiuba, S. and Okorie, J. E. (2010). "Methicillin Resistant Staphylococcus aureus (MRSA) Amongst Students and Susceptibility of MRSA to Garcinia kola Extracts". Nig. J. Microbiology: 24 (1), 2043 - 2047.

Quinn, P. J., Carter, M. E., Markey, B. K. and Carter, G. R. (2000). Staphylococcus species In: Clinical veterinary microbiology, Mosby, Edinburgh, pp. 118-126.

Rayner, C. and Munckhof, W. J. (2005). Antibiotics currently used in the treatment of infections caused by Staphylococcus aureus. Intern. Med. J. $35 \quad$ (2): $3-16$. http://dx.doi.org/10.1111/j.14440903.2005.00976.x PMid: 16271060

Sofowora, A. (1996). Research on medicinal plants and traditional medicine in Africa. Journal of Alternative and Complementary Medicine. 2(3):365-372.

Tiwara, R., Das, K. and Shrivastava, D. K. (2010). Techniques for evaluation of medicinal plant products as antimicrobial agent: Current methods and future trends. Journal of Medicinal Plants Research. 4: 104-111.

Waldvogel, F. A. (2000). Staphylococcus aureus. In: GL Mandell, RG Douglas \& JE Bennett (ed.), Principles and practices of infectious disease, 3rd ed. Churchill Livingstone, Philadelphia, Pennsylvania, USA. p. 1754-1777. 